\title{
Efficient Synthesis of Pharmaceutically Relevant Prochiral Heterocyclic Aminoketones
}

\author{
Ágnes Lakó1,2*, László Poppe, Ricardo Mendonça² \\ ${ }^{1}$ Department of Organic Chemistry and Technology, Faculty of Chemical Technology and Biotechnology, Budapest University of \\ Technology and Economics, 1111 Budapest, Múegyetem rkp. 3, Hungary \\ 2 Hovione Farmaciência, Campus do Lumiar, Edifício R, Estrada do Paço do Lumiar, 1649-038 Lisbon, S.A., Portugal \\ * Corresponding author, e-mail: alako@hovione.com
}

Received: 18 May 2020, Accepted: 15 June 2020, Published online: 18 January 2021

\section{Abstract}

In this work, we report a practical method for alkylation of saturated heterocycles with chloroacetone yielding prochiral heterocyclic ketones, including previously not described molecules. The desired building blocks were obtained with high yields in hydrochloric salt forms, without the need for chromatographic purification.

\section{Keywords}

prochiral aminoketones, saturated amine heterocycles, chloroacetone, alkylation, selective precipitation

\section{Introduction}

Prochiral aminoketones bearing different saturated heterocycles represent an important group of building blocks that can be utilized for the synthesis of active pharmaceutical ingredients containing (optically active) polyamines (such as selective $\mathrm{P} 2 \mathrm{X} 3$ receptor antagonist $\mathrm{RO}-85$ for inflammatory pain (1) [1], potential anticancer agent LPA2 (EDG4) antagonists [2], anti-inflammatory Cancer Osaka thyroid (COT) kinase inhibitors [3], potential antimalarial 4-aminoquinoline derivatives [4]), amino alcohols (such as analgesic 5-HT receptor agonists (2) [5]) and oximes (e.g. potential antibacterial agent 3 [6]) (Fig. 1).

Based on literature, a variety of reactions can be employed for the synthesis of the saturated heterocyclic aminoketones (Fig. 2), such as Grignard-type substitution (I) [7],

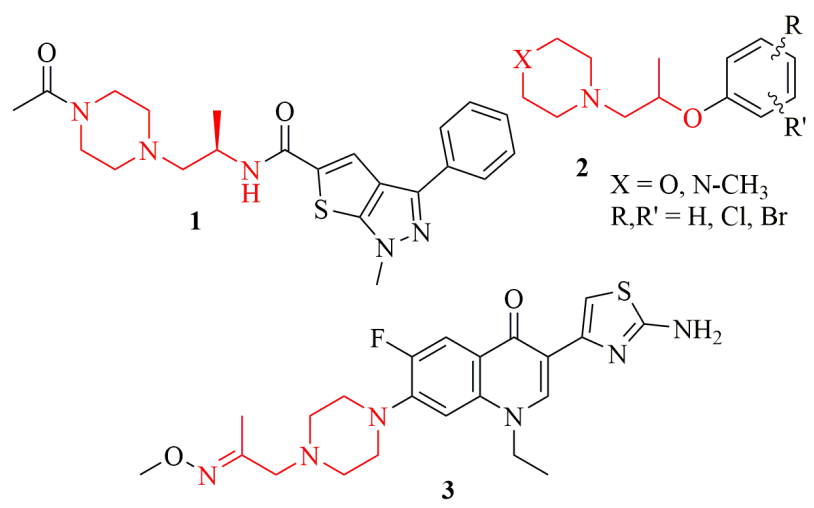

Fig. 1 API candidates intermolecular $\alpha$-carbonyl carbene insertion (II) [8], alkylation with chloroacetone (III) [9], Rabe amination (IV) [10], alcohol amination (V) [11] and multicomponent alkylation (VI) [12]. However, most of them require expensive catalysts ( $\mathrm{Ru}$-complex, $\mathrm{CuNiAlO}_{\mathrm{x}}$ or $\mathrm{Ru}_{3}(\mathrm{CO})_{12}$ ), inert atmosphere, elevated temperatures (up to $150{ }^{\circ} \mathrm{C}$ ) or operate with lower yields (20-37\%) and long reaction times (20-24 h).

Herein we describe a rapid and catalyst-free method for the synthesis of different aminoketones starting from the respective saturated heterocycles.

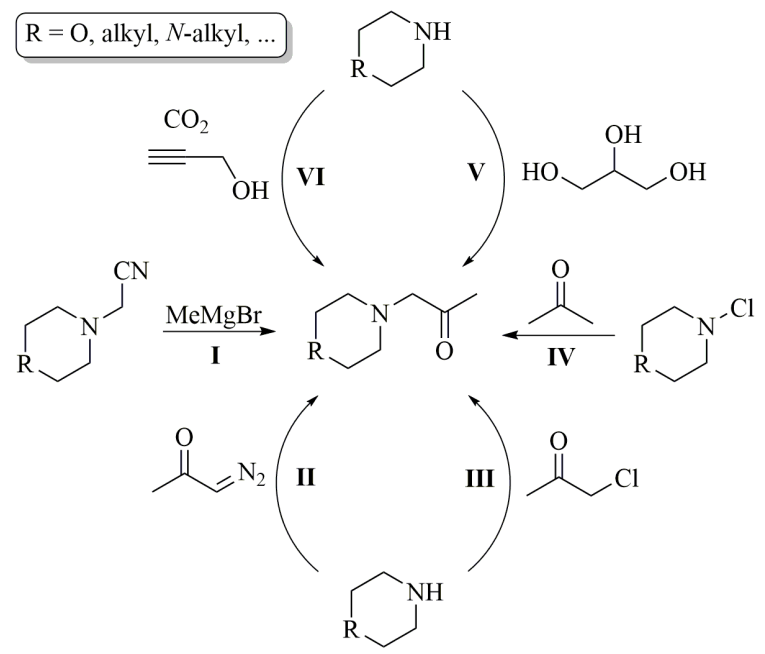

Fig. 2 Published syntheses of saturated heterocyclic aminoketones 


\section{Results and discussion}

For the synthesis of the aminoketones, the alkylation approach of the corresponding saturated amine heterocycle with chloroacetone (5) was chosen (Fig. 2, Method III). The commercially available morpholine (4a) proved to be suitable as a model compound for the optimization. At the start, the method widely used previously by our research group for the synthesis of various acetone-derivatives was employed. Although this method published by Martínez-Peragón et al. [13] provided full conversion within 4.5 hours, it required chromatographic purification.

However, column chromatography is often challenging when purifying basic compounds due to the ionic interactions with ionized silanol groups of silica gel [14]. Furthermore, as the target compounds are non-UV-active, the process cannot be directly followed by a UV detector and requires staining for visualization. Thus, an alternative work-up of the reaction mixture was introduced: by adjusting the $\mathrm{pH}$ of the aqueous phase, amines can be extracted with an organic solvent (usually, EtOAc, DCM). However, in the case of morpholine (4a) only quite moderate isolated yield of the alkylation product (6a) could be achieved due to its high solubility in the aqueous phase either under acidic or basic conditions (Table 1, Entry 1). Since both the starting material and the product are soluble in water, a work-up excluding this solvent was necessary. Acetone was replaced with non-miscible low-boiling point solvent methyl tert-butyl ether (MTBE) (Table 1, Entries 2-4).

For the synthesis of $\mathbf{6 a}$, two methodologies were developed (Fig. 3 and Table 1). The first method (Method A) used potassium carbonate $\left(\mathrm{K}_{2} \mathrm{CO}_{3}\right)$ as external base. Similar to the process in acetone, $\mathrm{K}_{2} \mathrm{CO}_{3}$ is not soluble in MTBE

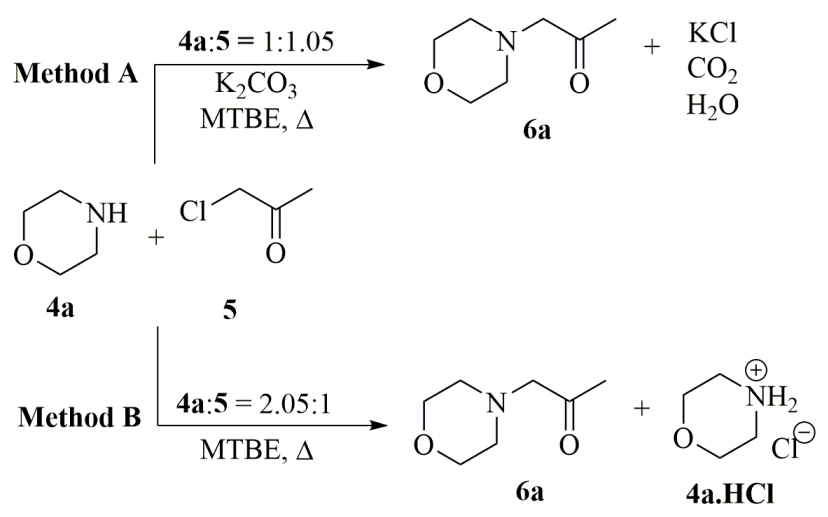

Fig. 3 Methods for alkylation of morpholine (4a) with chloroacetone (5)

which simplifies the work-up procedure as all inorganic byproducts can be removed by filtration. As the amine heterocycles generally have a $\mathrm{p} K_{\mathrm{a}}$ value around 9-11 (in case of 6a $\mathrm{p} K_{\mathrm{a}}=9.0$ ), the second method (Method B) applied morpholine (4a) in 2-fold excess to chloroacetone (5) also as base to capture the forming hydrochloric acid. Moreover, in case of Method B the forming 4a.HCl readily precipitates from the solution, further simplifying the composition of the reaction mixture.

In the reaction of two equivalents of $\mathbf{4 a}$ with $\mathbf{5}$ at room temperature, full conversion could not be reached even after $48 \mathrm{~h}$ (Table 1, Entry 3), in contrast to the reaction under reflux which completed in $8 \mathrm{~h}$ (Table 1, Entry 4). While the reaction employing two equivalents of $\mathbf{4 a}$ for 5 resulted in quantitative yield (Table 1, Entry 4), the use of one equivalents of $\mathbf{4 a}$ for $\mathbf{5}$ in the presence of $\mathrm{K}_{2} \mathrm{CO}_{3}$ as external base led to considerably lower yield, although TLC indicated full conversion (Table 1, Entry 2: Method A). The reason for the decreased yield can be explained by inspection of the filter cake's composition. It was confirmed by low-field benchtop NMR (Fig. 4) that the solid from the reaction

Table 1 Optimization of the alkylation of morpholine (4a) with chloroacetone (5)<smiles>C1COCCN1</smiles>

4a

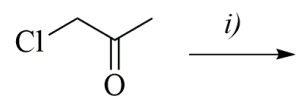

5

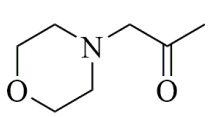

6a

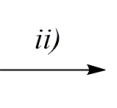

i)

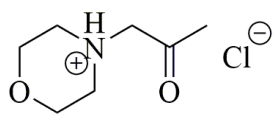

$7 \mathbf{a}$

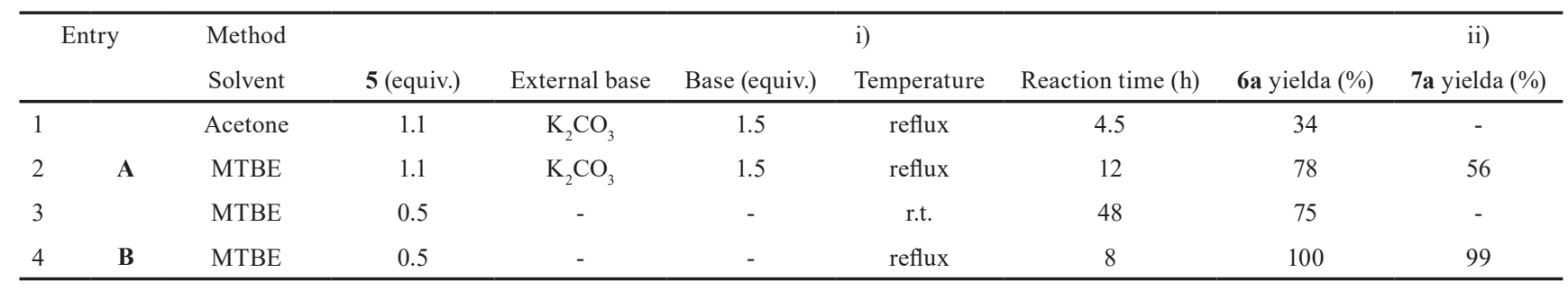

${ }^{a}$ Reaction conditions: $i$ ) morpholine $\mathbf{4 a}(1000 \mu \mathrm{L})$ in $10 \mathrm{~mL}$ solvent, 1.1 or 0.5 equiv. of 5 and 1.5 equiv. $\mathrm{K}_{2} \mathrm{CO}_{3}$ if indicated, temperature as indicated. ii) 1.05 equiv. of $\mathrm{HCl}$ in dioxane (For experimental procedures and analytical characterization see Supplement.) 


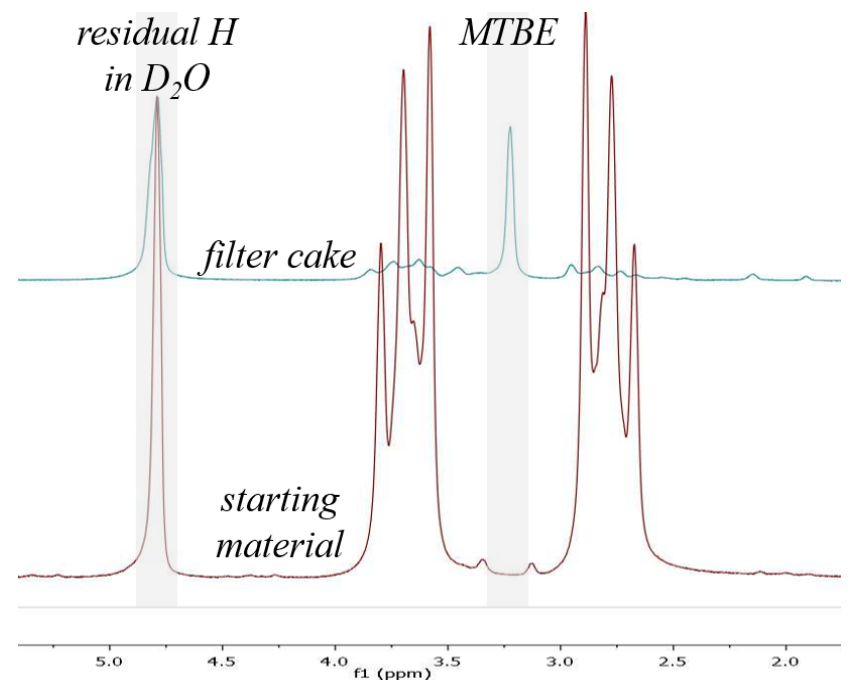

Fig. 4 Low-field NMR of the filter cake in reaction $\mathbf{4 a}$

mixture indeed contained the hydrochloride of the starting material (4a.HCl). Even though $\mathrm{K}_{2} \mathrm{CO}_{3}$ has a $\mathrm{p} K_{\mathrm{a}}$ value of $10.3,4 \mathbf{a}\left(\mathrm{p} K_{\mathrm{a}}: 9.0\right)$ is competing for capturing the forming hydrochloric acid. Unfortunately, the previously mentioned solubility issues did not allow organic extraction for quantification.

Upon isolation of $\mathbf{6 a}$ from MTBE, the hygroscopic properties of the obtained oil lead to absorption of water from air, preventing it from redissolving in MTBE. Nonetheless, it was confirmed by low-field benchtop NMR that the oil did not decompose

In order to enhance the stability of the aminoketone, the hydrochloride (7a) was formed by adding equimolar amount of $\mathrm{HCl}$ in dioxane to the solution of the intermediate (Table 1, Entry 2,4: Methods A and B). A faint-yellow solid readily precipitated from the organic solution; however, during filtration contact with air still resulted in quick absorption of water.

Under inert atmosphere, the product could be successfully isolated; furthermore, after drying, the obtained solid showed enhanced stability on air; even after $24 \mathrm{~h}$ standing on air the solid form was maintained.

This methodology was then applied for the synthesis of several further heterocyclic aminoketones (Table 2). As expected, the higher $\mathrm{p} K_{\mathrm{a}}$ values resulted in shorter reaction times compared to $4 \mathbf{a}$. This trend can be observed when comparing the reactions using external base as well. In most cases, the reactions by Method $\mathrm{A}$ (with $\mathrm{K}_{2} \mathrm{CO}_{3}$ ) required more time to complete (except for $\mathbf{4 d}$ ). However, despite the shorter reaction time, considerably lower yield was observed when using an external base. Since in this case the filter cake also contained the starting material, the shorter reaction time is the consequence of the starting material's precipitation as a hydrochloride salt. In three cases (4d, $\mathbf{4 e}$ and $\mathbf{4 f}$ ), the ketones were synthesized with high yields; however, the hydrochloric salts could not be isolated. Upon addition of the $\mathrm{HCl}$ in dioxane, the resulting hydrochloride salt stayed in a gummy state without precipitation. In addition, in case of $\mathbf{4} \mathbf{f}$, the starting material's hydrochloride did not precipitate either, but rather appeared as a dark-brown oil that could be separated by decanting the solution of the product. It is important to note, that in most cases the hydrochlorides possessed enhanced stability; however, two derivatives (7b and $\mathbf{7 g}$ ) liquefied quickly.

As piperazine $(\mathbf{4} \mathbf{j})$ is the most commonly applied saturated amine heterocycle for the synthesis of the active pharmaceutical ingredients mentioned in the Introduction, the reactions of this compound were more thoroughly explored. Analogous to the heterocycles bearing one secondary amine function, monosubstituted piperazine derivatives (4h and $\mathbf{4 i}$ ) can be only monoalkylated on the free amine group, while piperazine itself offers the possibility of symmetric dialkylation as well. Furthermore, when the piperazine derivatives possess two tertiary amine groups, two equivalents of $\mathrm{HCl}$ are required for precipitation, in contrast to monoalkylated compounds, where the product is precipitated with one equivalent. In case of $4 \mathrm{~h}$, the two reaction modes gave comparable yields, whereas the reactions of $\mathbf{4 i}$ resulted in $30 \%$ difference between yields (Table 2, Entry 8) indicating, that as in case of $\mathbf{4 a}$, this starting material might be precipitating in hydrochloride form as well. After confirmation via low-field NMR (Fig. 5), an aqueous-organic work-up of the filter cake successfully recovered non-water soluble $4 \mathbf{i}$.

Finally, the two examined reaction methodologies provide synthesis for both the mono- (6j) and dialkylated (6k) piperazine derivatives (Table 2, Entry 9). The preference for the different products can be understood when looking at the different reaction pathways (Fig. 6). When the inorganic external base is present (Method A), the monoalkylation reaction is complete in a few minutes forming $\mathbf{6} \mathbf{j}$, which then further reacts with $\mathbf{5}$, forming the desired $\mathbf{6 k}$. Applying Method B reaction conditions for substrate $\mathbf{4} \mathbf{j}$ results in $\mathbf{6 j}$ as major product, since extra addition of $\mathbf{5}$ leads to the precipitation of $\mathbf{6 j}$ hydrochloride, thus $6 \mathbf{k}$ cannot be synthesized with high yield. Although in theory this methodology is suitable for the selective synthesis 
Table 2 Alkylation of saturated heterocyclic amines (4b-j) with chloroacetone (5)

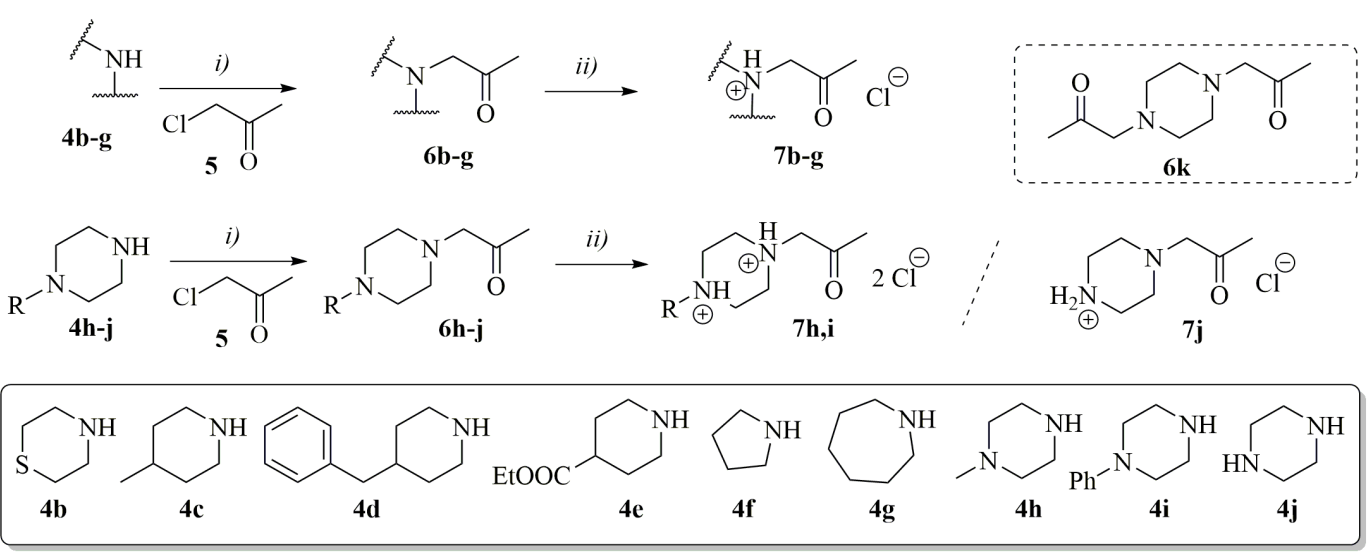

\begin{tabular}{|c|c|c|c|c|c|c|c|}
\hline Entry & Amine & $\mathrm{pK}_{\mathrm{a}}^{\mathrm{a}}$ & Aminoketone & Method & Reaction time (h) & 6 yield $^{\mathrm{b}}(\%)$ & 7 yield $^{\mathrm{b}}(\%)$ \\
\hline \multirow{2}{*}{1} & \multirow{2}{*}{$4 b$} & \multirow{2}{*}{9.1} & \multirow{2}{*}{$6 b$} & $\mathbf{A}$ & 4 & 88 & $73^{b}$ \\
\hline & & & & B & 4 & 100 & $83^{\mathrm{b}}$ \\
\hline \multirow{2}{*}{2} & \multirow{2}{*}{$4 c$} & \multirow{2}{*}{10.7} & \multirow{2}{*}{$6 c$} & $\mathbf{A}$ & 4 & 92 & 83 \\
\hline & & & & $\mathbf{B}$ & 2.5 & 100 & 85 \\
\hline \multirow{2}{*}{3} & \multirow{2}{*}{$4 d$} & \multirow{2}{*}{10.6} & \multirow{2}{*}{ 6d } & A & 2.5 & 59 & - \\
\hline & & & & B & 3.5 & 98 & - \\
\hline \multirow{2}{*}{4} & \multirow{2}{*}{$4 e$} & \multirow{2}{*}{9.8} & \multirow{2}{*}{$6 e$} & $\mathbf{A}$ & 5 & 94 & - \\
\hline & & & & B & 4 & 93 & - \\
\hline \multirow{2}{*}{5} & \multirow{2}{*}{$4 f$} & \multirow{2}{*}{10.5} & \multirow{2}{*}{$6 f$} & A & 6.5 & 81 & - \\
\hline & & & & B & 4 & 64 & - \\
\hline \multirow{2}{*}{6} & \multirow{2}{*}{$4 \mathrm{~g}$} & \multirow{2}{*}{10.3} & \multirow{2}{*}{$6 \mathrm{~g}$} & $\mathbf{A}$ & 6 & 94 & 95 \\
\hline & & & & B & 4.5 & 100 & 66 \\
\hline \multirow{2}{*}{7} & \multirow{2}{*}{$4 h$} & \multirow{2}{*}{9.3} & \multirow{2}{*}{$6 \mathrm{~h}$} & A & 12 & 82 & 76 \\
\hline & & & & B & 6 & 87 & 78 \\
\hline \multirow{2}{*}{8} & \multirow{2}{*}{$4 i$} & \multirow{2}{*}{9.0} & \multirow{2}{*}{$6 i$} & $\mathbf{A}$ & 9 & 72 & 62 \\
\hline & & & & B & 12.5 & 99 & 91 \\
\hline \multirow{2}{*}{9} & \multirow{2}{*}{$4 \mathbf{j}$} & \multirow{2}{*}{9.6} & $6 k$ & $\mathbf{A}$ & 7 & 64 & 42 \\
\hline & & & $6 j$ & B & 8 & n.d. ${ }^{d}$ & $74^{e}$ \\
\hline
\end{tabular}

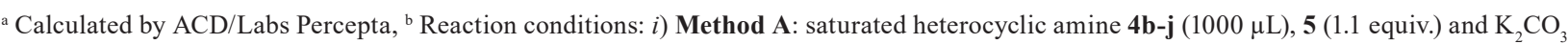

(1.5 equiv) in $10 \mathrm{~mL}$ MTBE, reflux; Method B: saturated heterocyclic amine $\mathbf{4 b}$-g $(1000 \mu \mathrm{L})$ and $\mathbf{5}$ ( 0.5 equiv.) in $10 \mathrm{~mL} \mathrm{MTBE}$, reflux. ii) $\mathrm{HCl}$ (1.05 equiv. for $\mathbf{4 a - g , j ; ~} 2.05$ equiv. for $\mathbf{4 h}, \mathbf{i})$ in dioxane, ${ }^{\mathrm{c}}$ The forming hydrochloride was recrystallized from ethanol/MTBE, ${ }^{\mathrm{d}}$ Not isolated, due to the complex reaction mixture, ${ }^{\mathrm{e}} \mathrm{NMR}$ yield (For experimental procedures and analytical characterization see Supplement.)

of $\mathbf{6 j}$, the desired product could not be completely isolated from the unreacted starting material and side-product $\mathbf{6 k}$. The ${ }^{1} \mathrm{H}-\mathrm{NMR}$ spectrum and the HRMS chromatogram of the crude mixture show that both $\mathbf{6 k}$ and $4 \mathbf{j}$ are present alongside with the desired product $\mathbf{6 j}$. After addition of equimolar amount of $\mathrm{HCl}$, the NMR and HRMS analyses of the precipitate indicate a mixture of $\mathbf{7 j}$ and $\mathbf{4 j}$. $\mathbf{H C l}$, as $6 \mathbf{k}$ requires two equivalents of $\mathrm{HCl}$ for precipitation. However, in the synthesis of the mono-alkylated compound, Method B does not make it possible to separate the monoalkylated $\mathbf{6 j}$ from the starting material.

\section{Conclusions}

In this work, two simple and robust methods were compared for the synthesis of various saturated heterocyclic aminoketones. The improved workup procedures do not need chromatographic purification due to selective precipitation of the hydrochloride form from the reaction media. The hydrochloride forms of the target compounds were obtained in good to excellent yields and showed enhanced stability on air compared to the free base forms. Furthermore, new compounds have been also synthesized with the developed methods. 


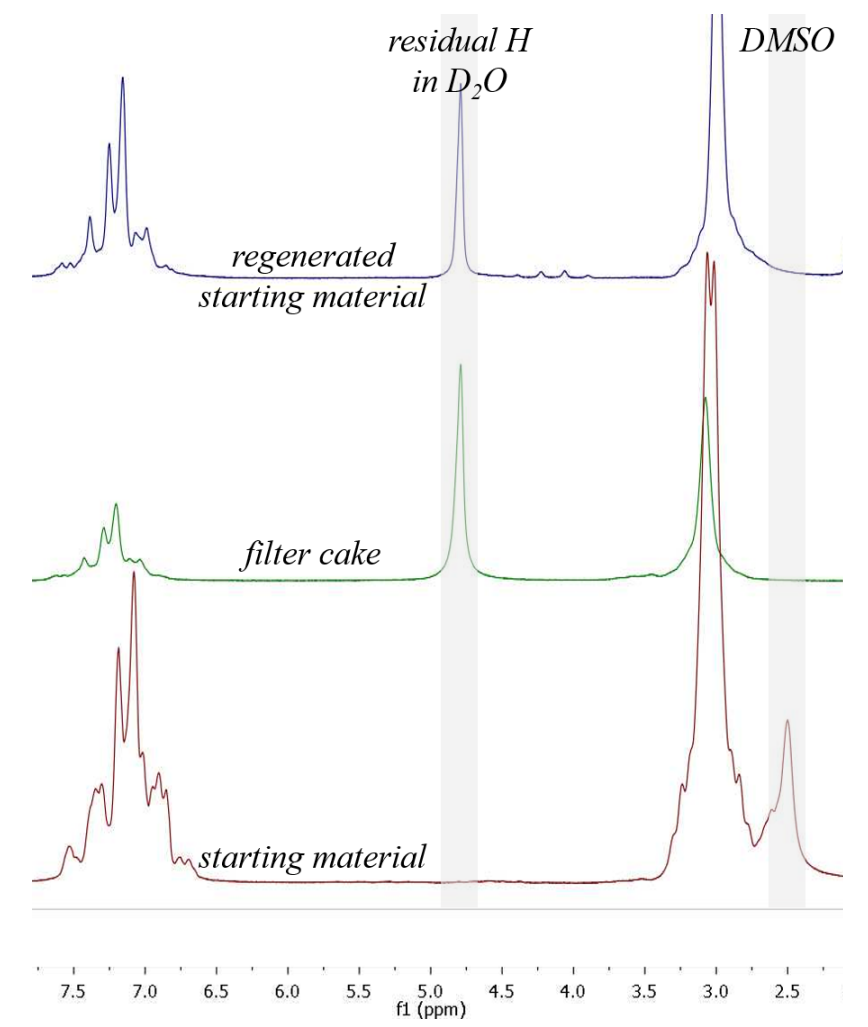

Fig. 5 Low-field NMR of the filter cake in reaction of $\mathbf{4 i}$

\section{References}

[1] Brotherton-Pleiss, C. E., Dillon, M. P., Ford, A. P. D. W., Gever, J. R., Carter, D. S., Gleason, S. K., Lin, C. J., Moore, A. G., Thompson, A. W., Villa, M., Zhai, Y. "Discovery and optimization of RO-85, a novel drug-like, potent, and selective $\mathrm{P} 2 \mathrm{X} 3$ receptor antagonist", Bioorganic \& Medicinal Chemistry Letters, 20(3), pp. 1031-1036, 2010.

https://doi.org/10.1016/j.bmcl.2009.12.044

[2] Beck, H. P., Kohn, T., Rubenstein, S., Hedberg, C., Schwandner, R., Hasslinger, K., Dai, K., Li, C., Liang, L., Wesche, H., Frank, B., An, S., Wickramasinghe, D., Jaen, J., Medina, J., Hungate, R., Shen, W. "Discovery of potent LPA2 (EDG4) antagonists as potential anticancer agents", Bioorganic \& Medicinal Chemistry Letters, 18(3), pp. 1037-1041, 2008.

https://doi.org/10.1016/j.bmcl.2007.12.024

[3] Glatthar, R., Stojanovic, A., Troxler, T., Mattes, H., Möbitz, H., Beerli, R., Blanz, J., Gassmann, E., Drückes, P., Fendrich, G., Gutmann, S., Martiny-Baron, G., Spence, F., Hornfeld, J., Peel, J. E., Sparrer, H. "Discovery of Imidazoquinolines as a Novel Class of Potent, Selective, and in Vivo Efficacious Cancer Osaka Thyroid (COT) Kinase Inhibitors", Journal of Medicinal Chemistry, 59(16), pp. 7544-7560, 2016.

https://doi.org/10.1021/acs.jmedchem.6b00598

[4] Kondaparla, S., Soni, A., Manhas, A., Srivastava, K., Puri, S. K., Katti, S. B. "Synthesis and antimalarial activity of new 4-aminoquinolines active against drug resistant strains", RSC Advances, 6(107), pp. 105676-105689, 2016.

https://doi.org/10.1039/c6ra14016e

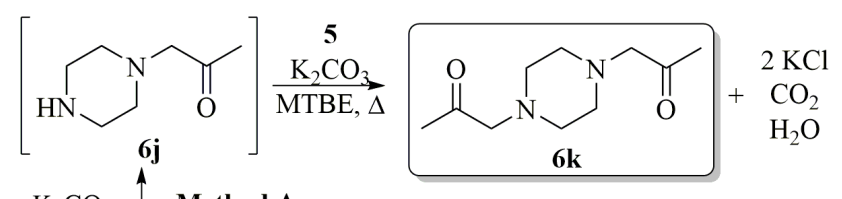

$\mathrm{K}_{2} \mathrm{CO}_{3} \uparrow$ Method A

$\mathrm{MTBE}, \Delta \quad \mathbf{4 j}: \mathbf{5}=1: 2.05$
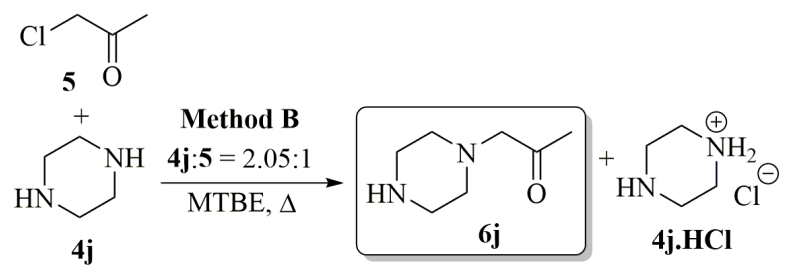

Fig. 6 Methods for alkylation of piperazine $(\mathbf{4 j})$ with chloroacetone (5)

\section{Declaration of competing interest}

The authors declare that they have no known competing financial interests or personal relationships that could have appeared to influence the work reported in this paper.

\section{Acknowledgments}

The authors are thankful to the Faculty of Pharmacy, University of Lisbon (FFULisboa) for providing analytical support.

[5] Ismaiel, A. M., Gad, L. M., Ghareib, S. A., Bamanie, F. H., Moustafa, M. A. "Synthesis of piperazino and morpholino derivatives of aryloxypropane with potential analgesic and possible antimigraine activities", Medicinal Chemistry Research, 20(3), pp. 381-387, 2011. https://doi.org/10.1007/s00044-010-9316-3

[6] Wang, L.-L., Battini, N., Bheemanaboina, R. R. Y., Ansari, M. F., Chen, J-P., Xie, Y.-P., Cai, G.-X., Zhang, S.-L., Zhou, C.-H. "A new exploration towards aminothiazolquinolone oximes as potentially multi-targeting antibacterial agents: Design, synthesis and evaluation acting on microbes, DNA, HSA and topoisomerase IV", European Journal of Medicinal Chemistry, 179, pp. 166-181, 2019. https://doi.org/10.1016/j.ejmech.2019.06.046

[7] Aitken, D. J., Beaufort, V., Chalard, P., Cladière, J.-L., Dufour, M., Pereira, E., Théry, V. "Theoretical and model studies on the chemoselectivity of a Grignard reagent's reaction with a combined aminonitrile-oxazolidine system", Tetrahedron, 58(29), pp. 5933-5940, 2002. https://doi.org/10.1016/S0040-4020(02)00501-X

[8] Del Zotto, A., Baratta, W., Rigo, P. "Highly chemoselective $\alpha$-diazo carbonyl insertion reactions into $\mathrm{N}-\mathrm{H}$ and $\mathrm{S}-\mathrm{H}$ bonds catalysed by $\left[\mathrm{RuCl}\left(\eta^{5}-\mathrm{C}_{5} \mathrm{H}_{5}\right)\left(\mathrm{PPh}_{3}\right)_{2}\right]$ ", Journal of the Chemical Society, Perkin Transactions 1, 21, pp. 3079-3081, 1999. https://doi.org/10.1039/a906332c

[9] Vorberg, R., Trapp, N., Zimmerli, D., Wagner, B., Fischer, H., Kratochwil, N. A., Kansy, M., Carreira, E. M., Müller, K. "Effect of Partially Fluorinated N-Alkyl-Substituted Piperidine2-carboxamides on Pharmacologically Relevant Properties", ChemMedChem, 11(19), pp. 2216-2239, 2016. https://doi.org/10.1002/cmdc.201600325 
[10] Scarpino Schietroma, D. M., Monaco, M. R., Bucalossi, V., Walter, P. E., Gentili, P., Bella, M. "The Rabe amination after a century: direct addition of N-heterocycles to carbonyl compounds", Organic \& Biomolecular Chemistry, 10(24), pp. 4692-4695, 2012. https://doi.org/10.1039/c2ob25595b

[11] Dai, X., Rabeah, J., Yuan, H., Brückner, A., Cui, X., Shi, F. "Glycerol as a Building Block for Prochiral Aminoketone, N-Formamide, and N-Methyl Amine Synthesis", ChemSusChem, 9(22), pp. 3133-3138, 2016

https://doi.org/10.1002/cssc.201600972

[12] Sasaki, Y., Dixneuf, P. H. "Ruthenium-catalyzed reaction of carbon dioxide, amine, and acetylenic alcohol", The Journal of Organic Chemistry, 52(19), pp. 4389-4391, 1987.

https://doi.org/10.1021/jo00228a046
[13] Martínez-Peragón, Á., Millán, A., Campaña, A. G., RodríguezMárquez, I., Resa, S., Miguel, D., de Cienfuegos, L. Á., Cuerva, J. M. "Ti/Ni-Based Multimetallic System for the Efficient Allylation of Carbonyl Compounds", European Journal of Organic Chemistry, 2012(8), pp. 1499-1503, 2012. https://doi.org/10.1002/ejoc.201101842

[14] McCalley, D. V. "The challenges of the analysis of basic compounds by high performance liquid chromatography: Some possible approaches for improved separations", Journal of Chromatography A, 1217(6), pp. 858-880, 2010.

https://doi.org/10.1016/j.chroma.2009.11.068 